\title{
PECULIARITIES OF SOCIAL COMPETENCE IN CHILDREN WITH DIFFERENT AUTISTIC LEVELS
}

\author{
Kateryna Ostrovska \\ katerynaostrova@gmail.com \\ Ivan Franko Lviv National University, Ukraine

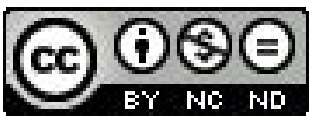

\begin{abstract}
The results of research of the social competence forming process in children with autistic disorders are presented in this work. It has been determined that the social competence range in children is dependent on the autism level. The factors of social adaptation in the children with different autism levels have been analyzed.
\end{abstract}

Key words: autism spectrum disorder, children, social competence, autism level.

\section{INTRODUCTION}

The problem of the socialization of disabled children, particularly the children with autism spectrum disorder, is connected with the fact that the majority of such children in Ukraine are excluded from the educational system and stay in big boarding schools or are kept their homes. Both special and professional education of these children is particularly connected with their social competence forming. However, the process of inclusion of such children into educational schools and preschool institutions is in its first stages. Thus, there is only one state preschool group and experimental school in L'viv (and in the whole of Ukraine) where autistic children can study. That is why we should adapt the foreign experience in social competence forming for autistic children.

\section{SOCIAL INTERVENTIONS FOR CHILDREN WITH AUTISTIC DISORDERS}

The analysis of foreign scientific literature has shown the great interest in the social skills forming in children within the autistic disorders range. In particular, there is the overview of more than 80 scientific publications where the results of conducted social interventions in groups of different aged children and with different functionality level is suggested in our research (Table 1).

In general, the social interventions can be characterized by some parameters such as: the interference method, the duration (periodicity), and the source group characterization. According to the interference method, the social interventions can be divided into 5 categories: 1) technological (technical tools usage: laptop, video surveillance, tape recorder, and TV); 2) interference with the parents participation. 
3) interference with the specialist participation; 4) interference with same-age children participation; 5) combined or multifunctional interferences. The general characteristic of the implemented social interferences is given in the table 1 . The detail list of Table 1 references is situated in Annex/

Table 1. The characteristic of social interventions aimed at social skills forming in children with autism spectrum disorder (*The figures correspond to method of intervention described in the above text)

\begin{tabular}{|l|c|c|c|c|c|c|c|c|c|c|c|c|}
\hline Age group & № & \multicolumn{3}{|l|}{ A kind of research } & \multicolumn{3}{|l|}{$\begin{array}{l}\text { The functionality } \\
\text { level }\end{array}$} & \multicolumn{3}{|l|}{$\begin{array}{l}\text { The intervention } \\
\text { method* }\end{array}$} \\
\cline { 2 - 15 } & Clinical & Group & $\begin{array}{l}\text { One- } \\
\text { time }\end{array}$ & low & medium & high & 1 & 2 & 3 & 4 & 5 \\
\hline $\begin{array}{l}\text { General } \\
\text { numbers }\end{array}$ & 82 & 3 & 12 & 67 & 26 & 33 & 23 & 10 & 4 & 36 & 16 & 16 \\
\hline $\begin{array}{l}\text { Preschool } \\
\text { age children }\end{array}$ & 35 & 2 & 2 & 31 & 19 & 22 & 9 & 2 & 4 & 21 & 5 & 9 \\
\hline $\begin{array}{l}\text { School age } \\
\text { children }\end{array}$ & 47 & 1 & 10 & 36 & 7 & 11 & 14 & 8 & 0 & 15 & 9 & 7 \\
\hline
\end{tabular}

Source - Author

The striking characteristic of the implemented social interventions is the group choice peculiarity according to the functionality level: in the table 1 we can notice that the interventions in higher functionality level children are increased. The high percentage of one-time interventions aimed at forming of the separate parameter can be included in the negative social intervention methods. It says about the system of lack of method aimed at the social competence forming in children with autistic disorders range, and the absence of source programs in social competence forming in children generally. The next shortcoming of analyzed investigations is the fact that there is only one intervention aimed at the social competence forming while the rest of interventions are directed into social skills forming.

\section{SOCIAL COMPETENCE APPROACH}

Today it is very important for the special education to develop a competent approach to people with autism development, choose the key competence and research the ways of realization of the mentioned approach in practice.

Nowadays the research of social competence has an interdisciplinary character (Bakhteyeva, 2001). According to Svitlana Bakhteyeva, the social competence consists of such components:

- "to know" - knowledge is needed for social activity realization; values that control the skills and habits usage;

- "to be able to" - the methods of a person's skills and habits realization to constitute themselves both in the internal experience and the external social activity; 
- "to achieve" - the accordance with the social demands of the person's activity and behavior; the person's ability to perform their functions, to follow their rights and duties at the appropriate age, social and cultural levels (Kalinina, 2004).

Thus, the social competence can be identified as the integrative personal formation that includes cognitive, active, moral and valuable components. It is very interesting to observe how these components are being changed in children with autistic spectrum disorders. At domestic practice autism is a phenomenon referred to by many representatives of science, education and social institutions (Shulzhenko, 2009; Skrypnyk, 2008; Lebedinska, \& Nikolska, 1991; Nikolska, Bayenskaya, \& Libling, 2007).

However, the level of understanding and perception of the problem of autistic personality by society, in general, and the branches of multistage educational system is quite low. The phenomenon of social competence is being widely researched in the foreign scientific literature (Mayes, 2007; Ingram, 2007; Bellini, 2008 etc.). Nevertheless, it should be admitted that the foreign scientists have essentially another approach to the social competence sphere definition. According to Janis Jacobs, the social competences include only the relationships in the group: speaking skills, emotion understanding, working with conflict, friendship skills (Meder, 2000). In this work we rely on domestic experience that is based on studying the personality theory study and its application in research ino social interactions between people.

That is why the aim of this work is the precondition analysis for the social competence forming in the children with autism spectrum disorder. Special attention is paid to the social competence comparison in the children with different autistic levels.

\section{EXPERIMENTAL METHODS}

The research was done with school age children in the first Ukraine experimental school where the children with autism are officially taken for studying. 50 children with officially diagnosed "autistic disorders range" were taken for this research.

The undermentioned methods were used in the research :

1. Binet-Simon scale for intelligence level determination.

2. Method of neuropsychological research according to Alexander Luria for psychophysical development level determination.

3. Childhood Autism Rating Scale (CARS) for autism level determination.

4. Assessment of social competence (ASC) for children and young adults with developmental disabilities.

Among the applied methods the usage of A.R. Luria's neuropsychological research should be explained. We have done the research in our work by means of the undermentioned method parts: orientation, adequacy, criticality, proof test, test on the reciprocal coordination, test on the conditional choice reaction, test on the dynamic praxis, test on the objective and acoustic gnosis, test on identification of spatial oriented simple figures and test on emotion identification. It was expected that this research would give us the possibility to identify the cognitive development peculiarities in the children with autism which, in its turn, would induce improvements in correctional and rehabilitative program design. 
The given results are processed by the statistical methods. Accordingly, the comparative, factorial and correlative analyses have been conducted for the results interpretation and obtaining the objective conclusion.

\section{EXPERIMENTAL RESULTS}

The division of researched children according to the autism level was the first stage of this research. We researched the autism level in accordance with CARS (Childhood Autism Rating Scale) method. We obtained such results in the process of research: $53 \%$ of researched children show the low autism level, $42 \%$-medium and 5\% - high level.

These indicators are regular for the children that study in the experimental school. In these days a small number of children with high autistic level study at this school. It witnesses that even at a school with the national experimental status for autistic children, the studying process can not involve children with high autistic level. That is why the day centre for children with high autistic level has been opened in L'viv on the level of "Vydkryte sertse" public organization. It can be attended by children after the 1-2 class in school and children that prepare before entering the school.

On the basis of the conducted factorial analysis indicators, gained in accordance with Binet-Simon's, A.R.Luria's and CARS' methods, five factors have been formulated, they can be described in such psychological meaning:

1) personal component;

2) activity component;

3) cognitive component;

4) emotional component;

5) age.

The complex of these components determines the forming level of some childre$n$ 's competences. If each factor is considered then four social competence spheres of children with autism can be separated and dynamics of their change with age can be observed. Considering the availability of substantial social competence dependence on the physical disorder degree in children, it is reasonable to set the competence differences in the children with different autistic level. We have used the results of the correlational analysis for setting of these differences in out work.

Such connections have been set on the basis of the conducted correlational analysis:

1) returned correlational connections between the autistic level and the activity component parameters - "name the objects", "count 4 coins" ( $\mathrm{r}=-0,6)$; and also direct correlational connection between the autistic level and the priceless object usage $(\mathrm{r}=-0,87)$. Thus, the children with the lower autistic level have more possibilities and get more involved in different activities.

2) direct correlational connection between the autistic level and the anxiety $(\mathrm{r}=0,8)$. Thus, the children with high autistic level are characterized by high anxiety level. They cannot sit quietly and are discomforted. Accordingly, the decrease of the autistic level leads to the general balance improvement and more adequate emotional reaction. 
3) direct correlational connection between the autistic level and the imitation $(\mathrm{r}=0,72)$. Thus, the children with high autistic levels are characterized by imitation without understanding of their moves content. The decrease of the autistic level leads to better understanding of their behavior motives and sensibility of their actions.

4) direct correlational connection between the autistic level and overcoming the obstacle $(r=0,84)$. Thus, the children with high autistic level perceive the environment as a threat and in order to avoid this threat they try to overcome the obstacles. In most cases, they are hyperactive. The decrease of the autistic level in the result of the correlational classes and the age influences positively on children that leads to increase of their equability and physical activity decrease.

Thus, on the basis of the correlational analysis the increase of social competences level with the autistic level decrease in children in the intellectual, emotional and activity spheres has been determined. The correlational analysis results do not detect the relationships between the autistic level and the personal development components. We think that it is connected with the fact that about the personal component we can talk only for high functional children within the autism range. Children with low and medium levels do not consider their " $\mathrm{I}$ " in the result of substantial disorder in the integrative functions of the brain that is why it is difficult for them to talk about the formed personal component.

As a result, we can propose two schemes which generalize the social competences in the children with different autistic level (scheme 1 and 2).

Scheme 1. Social competence structure for high functional people with autistic disorders range.

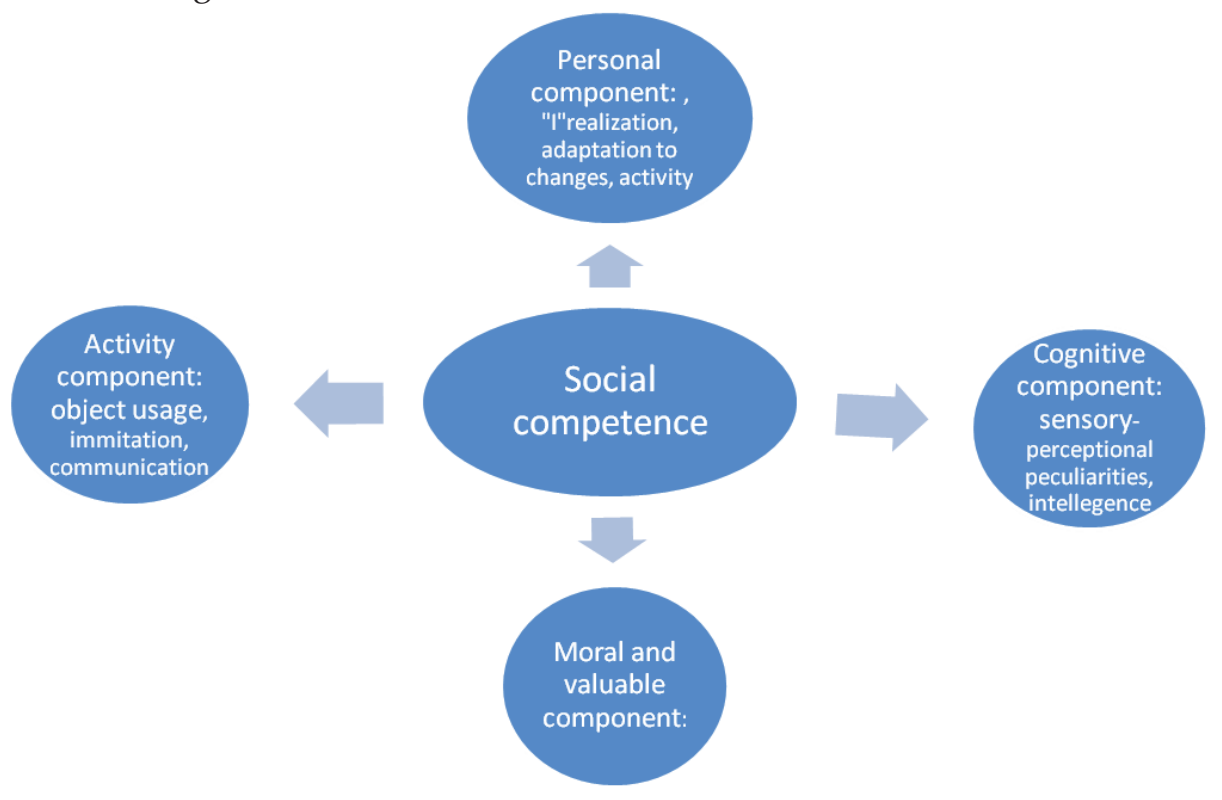

Source: Author 
Scheme 2. Social competence structure for people with high and medium autistic level.

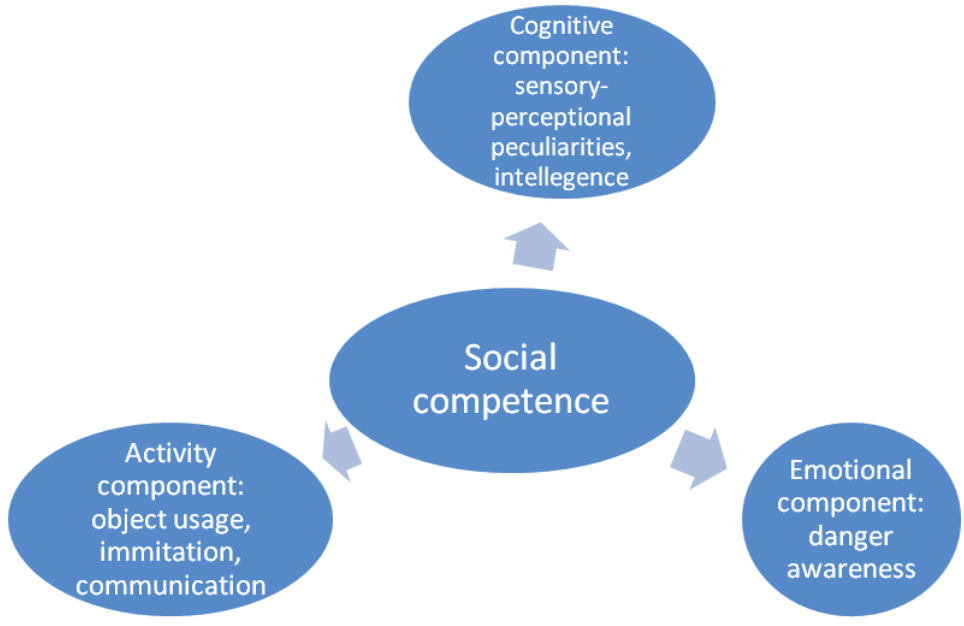

Source: Author

Using the given schemes we have carried out social interventions for the preschool group and the same age autistic children. The preschool group consists of $63-5$ years-old children. We have used the intervention to these children with the elements of ABA therapy. The school class contains 11 8-12 year-old children. And here we have used the intervention based on ABA and TEACCH therapy elements. The interventions have lasted for 52 weeks 2-3 times a week with duration 45 minutes. The preliminary and end evaluations of progress in children's social competence forming have been done with usage of an ASC questionnaire (Assessment of social competence for children and young adults with developmental disabilities by Meyer, Reichle, McQuarter, \& Cole, 1985),

ASC contains 252 separate questions organized in 11 functions: initiation, self-control, rule following, positive corroboration securing, negative reciprocal connection securing, answer to signals, help acceptance, help offering, ability to make a choice, ability to cope with negativism and interaction stopping. We have tried to adapt this methodology and classified 11 functions in accordance with four components of social competence (scheme 1). These results are presented in table 3.

\section{DISCUSSION}

It is necessary to admit the gradual approach to social competence forming in children. The process of social competence forming in the children with autistic disorder range includes 3 stages: social adaptation, socialization, and social competence forming itself. Taking into account the symptomatology of this disease, it is very important for the children with autism to realize the first stage - to revert to society. Later we will discuss factors that should be taken into account on the first stage of social competence forming: 
1. Peculiarities of the perceptual sphere of children with autism

2. Peculiarities of the interaction with people.

Regarding the perceptual sphere, it is very important to take into consideration the availability of abrupt polarization in children with autism between such perceptual characteristics:

Table 2. Perceptual characteresitcs of children with autism spectrum disorder

\begin{tabular}{|l|l|}
\hline Taste, smell, and touch & Aural reaction \\
\hline $\begin{array}{l}\text { Considerable development of such spheres, } \\
\text { mainly, indicated at low functional activity } \\
\text { of people with autism }\end{array}$ & $\begin{array}{l}\text { Development of this sphere correlates } \\
\text { greatly with gnosis indicators, the child with } \\
\text { autistic range intellectual development }\end{array}$ \\
\hline
\end{tabular}

Source: Author

The results of the first table 2 column can be explained by the compensatory mechanism activity. If a child has such spheres as verbal and non-verbal communication greatly impaired, the human organism tries to compensate for these disorders by means of other resources (taste, smell, and touch). That is why hypersensitivity and over vulnerability in the mentioned spheres are observed in the children with high autistic level, the same as in animals.

The results of the second table 2 column are very important for the correlational and rehabilitative programs application. They indicate the high influence of perceived information through the ear on its understanding and comprehension. That is why it is very important for the children's intellectual sphere development to make them enter the "listening" state. It is easier to do with the high functional children, however, it is very difficult to do it with the children with high autistic level.

Over anxiety and the constant physical activity are two factors that distract these children from concentrating. The difference between these groups is noticed also on the physiological level - the alpha-rhythm on the brain encephalogram is almost absent in the children with high autistic level. The alpha-rhythm is a vibration of the low frequency with the periodicity of 6-7 times per second. It is likely that the availability of such frequencies in the healthy children and in the high functional children with disorders of other nosologies harmonizes the psychological processes and removes the anxiety state. The alpha-rhythm in healthy people is in a state of increased anxiety and trance, however, it is well divided in a state of tranquility and dream.

One of the methods of people calming is psychotherapy treatment where the practice of rhythmic repetitions, facile language and slow music has been used. It is obvious that the same practice should be used for the hyperactive children calming. The practice of work with the hyperactive children with autism in Lviv "Open Heart" centre has shown that systematic participation in prayers, constant poem repetition and singing simple songs have a striking influence on such children. As the result of long-term practice those children have become more tranquil, open to "listening", and, respectively, to a sense of understanding things.

The fact of the direct correlational connection establishment between the "aural reaction" and the social competence personal component parameters, such as: "to determine their sex" $(r=0,82)$ and "to name their surname" $(r=0,82)$, has been very 
important for the correctional work. It means that the listening skill leads to individual establishment of person with autism, fosters their " $\mathrm{I}$ " realization, self-awareness and self-control elements forming.

One more very important perceptional sphere is the visual reaction. It is necessary to remember that the disorders of this sphere are observed in people with autism. However, in accordance with the correlational analysis data there is the direct correlational connection between the visual reaction and the understanding and intelligence $(\mathrm{r}=0,6)$ detected that justifies the importance of correction programs planning aimed at the visual reaction supporting for the cognitive competence forming in the children with autism.

That is why the development of perceptual sphere in children with autism induces their self-integration that leads to self-awareness and child's development as personality.

However, the consideration of the children social interaction peculiarities in the group is very important for the development of the social competence. On the high functioning level it is reasonable to talk about the acceptance of some rules, social behavior standards, conducting and understanding values system by child. On the low child's functioning level social interaction with other children comes to communication and emotional reaction revealing. Therefore, it is necessary for their social adaptation to work on the communication improvement, the emotion reaction revealing, and precaution of aggressive behavior to children and teachers.

The immediate task of social adaptation of the children with high autistic level is the correctional programs complex aimed at the sensory integration and connected environment perception. The effectiveness of these programs application is in the auto stimulation and aggression level decrease. At this stage such the child can be involved in the group classes and his/her socialization can be implemented.

The third stage, namely the social competence forming in the children with autistic disorders range, is implemented in the group, where the child "notices" the other children, is able to "listen", "see" and enter the communication process. It is understandable that such relationships will have some emotional coloring that later can lead to the friendship elements appearance or to conflict.

As a result of the social interventions implementation in accordance with described stages in the preschool age group and the pupils with autism spectrum disorder, we have gain some changes in their social competences (see table 3)

In accordance with table 3 results we can make the preliminary findings:

the applied social methods have been quite effective: almost all social competence parameters are substantially improved after the formulated experiment.

The social competence in the children with autistic disorder range depends on the autistic level: the higher autistic level, the less social competence is formulated in children.

The moral, valuable and personal components of the social competence are weakly developed in the children with high autistic level. Moreover, the insignificant changes in these spheres have been detected after the formulated experiment end. Thus, the development of these spheres for such children demands more efforts and the further research. 


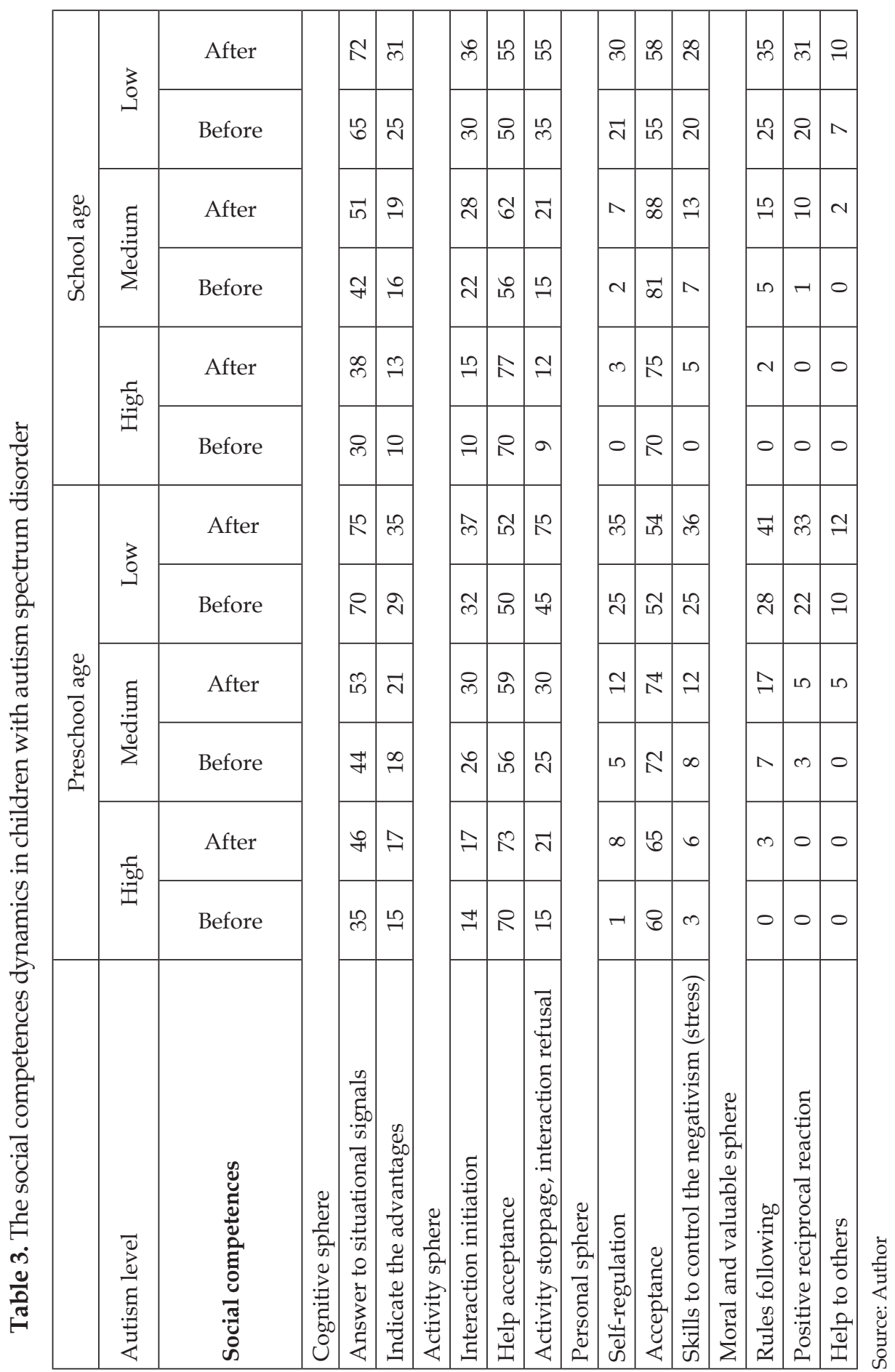


It is very important to admit the acceptance that indicators decrease in the children with high functional level of preschool and school ages. We think that it is connected with the ability to the adaptation and the manipulation for such children and reminds us of the behavior of the healthy children.

\section{CONCLUSION}

On the basis of the conducted research the analysis of preconditions to the social competence in the children with autism spectrum disorder has been put into practice. It has been found that the social competences range in children depends greatly on the autistic level. Thus, in the children with low autistic level four social competences components have been singled out: cognitive, activity, moral-valuable and personal. In the children with high and medium autistic levels the formulated social competences components are significantly reduced and include cognitive, activity and emotional components. The process of the social competences forming in the children with autistic disorders includes three stages: social adaptation, socialization and social competences forming the self. It has been shown that in the social adaptation stage in the children with high autistic level is very necessary to work with communication, emotional reactions and aggressive behavior precaution regarding children and their teachers. The correctional programs at this stage should be aimed at the integration of children's sensorial sensations.

The used social interventions for preschool and school age autistic children with ABA and TEACCH elements therapies usage has been found to be very effective: almost all the social competences parameters significantly improved after intervention. However the applied method has certain limitation. The obtained results have shown that moral, valuable and personal components of the social competence are weakly developed in the children with high autistic level. There are no significant changes of these spheres after the social interventions. Thus, the development of these spheres for the difficult children demands more efforts and the further researches.

\section{ANNEX}

The table 1 analysis shows that according to the interference method the most spread interventions are with the specialist participant interference (therapeutists, psychologists and teachers) (i.e. Boyd, Conroy, Mancil, Nakao, \& Alter, 2007; Carter, 2001; Crozier, \& Tincani, 2007; DeQuinzio, Townsend, Sturmey, \& Poulson, 2007; Gena, 2006; Hancock, \& Kaiser, 2002; Ingersoll, Dvortcsak, Whalen, \& Sikora, 2005; Ingersoll and Schreibman, 2006, Kasari, Freeman, \& Paparella, 2006; Kern, Wolery, \& Aldridge, 2007; Kohler, Anthony, Steighner, \& Hoyson, 2001; Kroeger, Schultz, \& Newsome, 2007; MacDuff, Ledo, McClannahan, \& Krantz, 2007; Smith, Goddard, \& Fluck, 2004, Whalen, \& Schreibman, 2003 for preschool age children and Bock, 2007, Fisher, \& Happe, 2005; Koegel, Werner, Vismara, \& Koegel, 2005; Lee, McComas, \& Jawor, 2002; LeGoff, 2004; LeGoff, \& Sherman, 2006; Lopata, Thomeer, Volker, Nida, \& Lee, 2008; Owens, Granader, Humphrey, \& Baron-Cohen, 2008; Sarokoff, 
Taylor, \& Poulson, 2001 for school age children). However, it has been suggested in the most analyzed works that the interventions with same age children participants give the best results (Chan, Lang, Rispoli, O’Reilly, Sigafoos, \& Cole, 2010; Garfinkle, \& Schwartz, 2002; Kohler, Greteman, Raschke, \& Highnam, 2007; Nelson, McDonnell, Johnston, Crompton, \& Nelson, 2007; Petursdottir, McComas, McMaster, \& Horner, 2007; Zercher, Hunt, Schuler, \& Webster, 2001; Betz, Higbee, \& Reagon, 2008; Ganz, \& Flores, 2008; Jones, Carr, \& Feeley, 2006; Jung, Sainato, \& Davis, 2008; Kern, \& Aldridge, 2006; Sawyer, Luiselli, Ricciardi, \& Gower, 2005 for preschool age children and Cotugno, 2009; Delano, \& Snell, 2006; DeRosier, Swiek, Davis, McMillen, \& Mattheews, 2011; Ganz; Kaylor, Bourgeois, \& Hadden, 2008; Koenig, White, Pachler, Lau, Lewis, Klin, \& Scahill, 2010; Kuhn, Bodkin, Devlin, \& Doggett, 2008; Lee, Odom, \& Loftin, 2007; Owen-DeSchryver, Carr, Cale, \& Blakeley-Smith, 2008; Thiemann, \& Goldstein, 2001; Laugeson Frankel, Gantman, Dillon, \&Mogil, 2012; Liber, Frea, \& Symon, 2008; Locke; Rotheram-Fuller, \& Kasari 2012; Loftin, Odom, \& Lantz, 2008; Morrison, Kamps, Garcia, \& Parker, 2001; McMahon, Vismara, \& Solomon 2012; Scheeren, Koot, \& Begeer 2012; Thiemann, \& Goldstein, 2004 for school age children). It is obvious that the number is not very large owing to the forming group guarantee complexity. The interventions with technical tools usage are more effective at school age. That is why the numbers in preschool age children (Bellini, Akullian, \& Hopf, 2007; Simpson, Langone, \& Ayres, 2004) is less than in school age children (Buggey, 2005; Charlop-Christy, \& Daneshvar, 2003; LeBlanc, Coates, Daneshvar, Charlop-Christy, \& Morris, 2003; Nikopoulos, \& Keenan, 2004; Nikopoulos, \& Keenan, 2007; Scattone, 2008; Delano, 2007; Sherer, Pierce, Pardes, Kisacky, Ingersoll, \& Schreibman, 2001). According to the table, the interventions from the parents' side are limited and practiced only for preschool age children (Aldred, Green, \& Adams, 2004, Ingersoll, \& Gergans, 2007; Schertz, \& Odom, 2007; Vismara, \& Lyons, 2007). Obviously, it is connected with the low paternal motion activity and the relatively low parental professional competence. Moreover, the intervention with the combined method usage is not very frequent (Apple, Billingsley, \& Schwartz, 2005; Gena, Couloura, \& Kymissis, 2005; Maione, \& Mirenda, 2006 for preschool children and Sansosti and Powell-Smith, 2008; Shabani, Katz, Wilder, Beauchamp, Taylor, \& Fischer, 2002 for school age children).

\section{REFERENCES}

Aldred, C., Green, J., \& Adams, C. (2004). A new social communication intervention for children with autism: Pilot randomised controlled treatment study suggesting effectiveness. Journal of Child Psychology and Psychiatry, 45, 1420-1430.

Apple, A. L., Billingsley, F., \& Schwartz, I. S. (2005). Effects of video modeling alone and with self-management on compliment- giving behaviors of children with high-functioning ASD. Journal of Positive Behavior Interventions, 7, 33-46.

Bachteeva, S.S. (2001). Формирование соииальной компетентности в процессе обучения иностранному языку В ВУЗе экономического профиля [Formation of social competence at process of education of foreing language at universities of economical profile]. Каzan: Институт профессионального образования РАО.

Bellini S. (2006). Building Social Relationships: A Systematic Approach to Teaching Social Interaction Skills to Children and Adolescents with Autism Spectrum Disorders and Other Social Difficulties, Kanzas: Autism Asperger Publishing. 
Bellini, S., Akullian, J., \& Hopf, A. (2007). Increasing social engagement in young children with autism spectrum disorders using video self-modeling. School Psychology Review, 16, 80-90.

Betz, A., Higbee, T. S., \& Reagon, K. A. (2008). Using joint activity schedules to promote peer engagement in preschoolers with autism. Journal of Applied Behavior Analysis, 41, 237-241.

Bock, M. A. (2007). The impact of social-behavioral learning strategy training on the social interaction skills of four students with Asperger syndrome. Focus on Autism and Other Developmental Disorders, 22, 88-95.

Boyd, B. A., Conroy, M. A., Mancil, G. R., Nakao, T., \& Alter, P. J. (2007). Effects of circumscribed interests on the social behaviors of children with autism spectrum disorders. Journal of Autism and Developmental Disorders, 37, 1550-1561.

Buggey, T. (2005). Video self-modeling applications with students with autism spectrum disorder in a small private school setting. Focus on Autism and Other Developmental Disabilities, 20, 52-63.

Carter, C. M. (2001). Using choice with game play to increase language skills and interactive behaviors in children with autism. Journal of Positive Behavior Interventions, 3, 131-151.

Chan, J. M., Lang, R., Rispoli, M., O'Reilly, M., Sigafoos, J., \& Cole, H. (2010). Use of peer-mediated interventions in the treatment of autism spectrum disorders: A systematic review. Research in Autism Spectrum Disorders. J Autism Dev Disord, 40, 149-166, 163.

Charlop-Christy, M. H., \& Daneshvar, S. (2003). Using video modeling to teach perspective taking to children with autism. Journal of Positive Behavior Interventions, 5, 12-21.

Cotugno, A.J. (2009). Social competence and social skills training and intervention for children with atusm spectrum disorders. J.Autism Development Disorder, 39, 1268-1277.

Crozier, S., \& Tincani, M. (2007). Effects of social stories on prosocial behavior of preschool children with autism spectrum disorders. Journal of Autism and Developmental Disorders, 37, 1803-1814.

Delano, M. E. (2007). Video modeling interventions for individuals with autism. Remedial and Special Education, $28,33-42$.

Delano, M., \& Snell, M. E. (2006). The effects of social stories on the social engagement of children with autism. Journal of Positive Behavior Interventions, 8, 29-42.

DeQuinzio, J. A., Townsend, D. B., Sturmey, P., \& Poulson, C. L. (2007). Generalized imitation of facial models by children with autism. Journal of Applied Behavior Analysis, 40, 755-759.

DeRosier, M.E., Swiek, D.C., Davis, N.O., McMillen, J.S, \& Mattheews, R. (2011). The efficacy of a social skills group invtervention for improving social behaviors in children with high functionaing autsm spectrum disorders. J.Autism Development Disorder, 41, 1033-1043.

Fisher, N., \& Happe', F. (2005). A training study of theory of mind and executive function in children with autistic spectrum disorders. Journal of Autism and Developmental Disorders, 35, 757-771.

Ganz, J. B., \& Flores, M. M. (2008). Effects of the use of visual strategies in play groups for children with autism spectrum disorders and their peers. Journal of Autism and Developmental Disorders, 38, 926-940.

Ganz, J. B., Kaylor, M., Bourgeois, B., \& Hadden, K. (2008). The impact of social scripts and visual cues on verbal communication in three children with autism spectrum disorders. Focus on Autism and Other Developmental Disabilities, 23, 79-94.

Garfinkle, A. N., \& Schwartz, I. S. (2002). Peer imitation: Increasing social interactions in children with autism and other developmental disabilities in inclusive preschool classrooms. Topics in Early Childhood Special Education, 22, 26-38.

Gena, A. (2006). The effects of prompting and social reinforcement on establishing social interactions with peers during the inclusion of four children with autism in preschool. International Journal of Psychology, $41,541-554$.

Gena, A., Couloura, S., \& Kymissis, E. (2005). Modifying the affective behavior of preschoolers with autism using in vivo or video modeling and reinforcement contingencies. Journal of Autism and Developmental Disorders, 35, 545-556.

Golan, O., \& Baron-Cohen, S. (2006). Systemizing empathy: Teaching adults with Asperger syndrome or high-functioning autism to recognize complex emotions using interactive multimedia. Development and Psychopathology, 18, 591-617.

Goldstein, H., Schneider, N., \& Theimann, K. (2007). Peer-mediated social communication intervention: When clinical expertise informs treatment development and evaluation. Topics in Language Disorders, 27, 182-199.

Hancock, T. B., \& Kaiser, A. P. (2002). The effects of trainerimplemented enhanced milieu teaching on the social communication of children with autism. Topics in Early Childhood Special Education, 22, 39-54.

Ingersoll, B., \& Gergans, S. (2007). The effect of a parentimplemented imitation intervention on spontaneous 
imitation skills in young children with autism. Research in Developmental Disabilities, 28, 163-175.

Ingersoll, B., \& Schreibman, L. (2006). Teaching reciprocal imitation skills to young children with autism using a naturalistic behavioral approach: Effects on language, pretend play, and joint attention. Journal of Autism and Developmental Disorders, 36, 487-505.

Ingersoll, B., Dvortcsak, A., Whalen, C., \& Sikora, D. (2005). The effects of a developmental, social-pragmatic language intervention on rate of expressive language production in young children with autistic spectrum disorders. Focus on Autism and Other Developmental Disabilities, 20, 213-222.

Ingram, D.H., Mayes, S.D., Troxell, L.B., Calhoun, S.L. (2007). Assessing children with autism, mental retardation, and typical development using the Playground Observation Checklist. Autism, 11 (4), 311-319.

Jones, E. A., Carr, E. G., \& Feeley, K. M. (2006). Multiple effects of joint attention intervention for children with autism. Behavior Modification, 30, 782-834.

Jung, S., Sainato, D. M., \& Davis, C. A. (2008). Using highprobability request sequences to increase social interactions in young children with autism. Journal of Early Intervention, 30, 163-187.

Kalinina N.V. (2004) Развитие социальной компетентности школьников в образовательной среде: психологопедагогическое сопровождение [Development of social competence of pupils at school: psychological-pedagogical support]. Uljanovsk: УИПКПРО

Kasari, C., Freeman, S., \& Paparella, T. (2006). Joint attention and symbolic play in young children with autism: A randomized controlled intervention study. Journal of Child Psychology and Psychiatry, 47, 611-620.

Kern, P., \& Aldridge, D. (2006). Using embedded music therapy interventions to support outdoor play of young children with autism in an inclusive community-based child care program. Journal of Music Therapy, 43, 270-294.

Kern, P., Wolery, M., \& Aldridge, D. (2007). Use of songs to promote independence in morning greeting routines for young children with autism. Journal of Autism and Developmental Disorders, 37, 1264-1271.

Koegel, R. L., Werner, G. A., Vismara, L. A., \& Koegel, L. K. (2005). The effectiveness of contextually supported play date interactions between children with autism and typically developing peers. Research and Practice for Persons with Severe Disabilities, 30, 93-102.

Koenig, K, White, S.W., Pachler, M., Lau, M., Lewis, M., Klin, A., Scahill, L. (2010). Promoting social skill development in children with pervasive development disordsers: a feasibility and effeacy study. J.Autism Development Disorder, 40. 1209-1218.

Kohler, F. W., Anthony, L. J., Steighner, S. A., \& Hoyson, M. (2001). Teaching social interaction skills in the integrated preschool: An examination of naturalistic tactics. Topics in Early Childhood Special Education, 21, 93-103.

Kohler, F. W., Greteman, C., Raschke, D., \& Highnam, C. (2007). Using a buddy skills package to increase the social interactions between a preschooler with autism and her peers. Topics in Early Childhood Special Education, 27, 155-163.

Kroeger, K. A., Schultz, J. R., \& Newsome, C. (2007). A comparison of two group-delivered social skills programs for young children with autism. Journal of Autism and Developmental Disorders, 37, 808-817.

Kuhn, L. R., Bodkin, A. E., Devlin, S. D., \& Doggett, R. A. (2008). Using pivotal response training with peers in special education to facilitate play in two children with autism. Education and Training in Developmental Disabilities, 43, 37-45.

Laugeson, E.A., Frankel, F., Gantman, A., Dillon, A.R., \& Mogil, C. (2012). Evidence-based social skills training for adolescents with autism spectrum disorders: The UCLA PEERS program. J Autism Dev Disord, 42,1025-1036.

Lebedinska, K.S., \& Nikolska, O.S. (1991) Диагностика раннего детского аутизма [Diagnostics of early childhood autism]. Moscov: Просвещение.

LeBlanc, L. A., Coates, A. M., Daneshvar, S., Charlop-Christy, M. H., \& Morris, C. (2003). Using video modeling and reinforcement to teach perspective-taking skills to children with autism. Journal of Applied Behavior Analysis, 36, 253-257.

Lee, R., \& Sturmey, P. (2006). The effects of lag schedules and preferred materials on variable responding in students with autism. Journal of Autism and Developmental Disorders, 36, 421-428.

Lee, R., McComas, J. J., \& Jawor, J. (2002). The effects of differential and lag reinforcement schedules on varied verbal responding by individuals with autism. Journal of Applied Behavior Analysis, 35, 391-402.

Lee, S., Odom, S. L., \& Loftin, R. (2007). Social engagement with peers and stereotypic behavior of children with autism. Journal of Positive Behavior Interventions, 9, 67-79.

LeGoff, D. B. (2004). Use of LEGO as a therapeutic medium for improving social competence. Journal of Autism and Developmental Disorders, 34, 557-571. 
LeGoff, D. B., \& Sherman, M. (2006). Long-term outcome of social skills intervention based on interactive LEGO play. Autism, 10,317-329.

Liber, D. B., Frea, W. D., \& Symon, J. B. G. (2008). Using timedelay to improve social play skills with peers for children with autism. Journal of Autism and Developmental Disorders, 38, 312-323.

Locke, J., Rotheram-Fuller, E., Kasari, C. (2012) Exploring the social impact of being a typical peer model for included children with autism spectrum disorder. J Autism Dev Disord.,42. 1895-1905.

Loftin, R. L., Odom, S. L., \& Lantz, J. F. (2008). Social interaction and repetitive motor behaviors. Journal of Autism and Developmental Disorders, 38, 1124-1135.

Lopata, C., Thomeer, M. L., Volker, M. A., Nida, R. E., \& Lee, G. K. (2008). Effectiveness of a manualized summer social treatment program for high-functioning children with autism spectrum disorders. Journal of Autism and Developmental Disorders, 38, 890-904.

MacDuff, J. L., Ledo, R., McClannahan, L. E., \& Krantz, P. J. (2007). Using scripts and script-fading procedures to promote bids for joint attention by young children with autism. Research in Autism Spectrum Disorders, $1,281-290$.

Maione, L., \& Mirenda, P. (2006). Effects of video modeling and video feedback on peer-directed social language skills of a child with autism. Journal of Positive Behavior Interventions, 8, 106- 118.

Matson, J. L. (2009). Applied Behavior Analysis for Children with Autism Spectrum Disorders, London: Springer.

Matson, J. L., Matson, M. L., \& Rivet, T. T. (2007). Social-skills treatments for children with autism spectrum disorders. Behavior Modification, 31, 682-707.

Mayes, S.D., Calhoun, S.L. (2007). Learning, Attention, Writing, and Processing Speed in Typical Children and Children with ADHD, Autism, Anxiety, Depression, and Oppositional-Defiant Disorder. Child Neuropsychology. Journal on Normal and Abnormal Development in Childhood and Adolescence, 13, 6.

Mayes, S.D.,\& Calhoun, S.L (2003). Ability profiles in children with autism: influence of age and IQ. Autism, 7, 65-80.

McDonald, M. E., \& Hemmes, N. S. (2003). Increases in social initiation toward an adolescent with autism: Reciprocity effects. Research in Developmental Disabilities, 24, 453-465.

McMahon, C.M.,Vismara, L.A., \& Solomon, M. (2012). Measuring changes in social behavior during a social skills intervention for hiher-functioning chidren and adolescents with atusm spectrum disorder. J.Autism Development Disorder, 41. 1269-1279.

Meder, J. (ed.). (2000). Rehabilitacja przewlekle chorych psychiczne [Rehabilitation of chronic mental patients]. Krakow: Biblioteka Psychiatrii Polskiej.

Meyer, L.H., Reichle, J., McQuarter, R., \& Cole D. (1985). Assessment of social competence (ASC): A scale of social competence functions. Minneapolis: University of Minnesota Consortium Institute for the Education of Severely Handicapped Learners.

Morrison, L., Kamps, D., Garcia, J., \& Parker, D. (2001). Peer mediation and monitoring strategies to improve initiations and social skills for students with autism. Journal of Positive Behavior Interventions, 3, 237-250.

Nelson, C., McDonnell, A. P., Johnston, S. S., Crompton, A., \& Nelson, A. (2007). Keys to play: A strategy to increase the social interactions of young children with autism and their typically developing peers. Education and Training in Developmental Disabilities, 42, 165-181.

Nikolska, O.S., Bayenskaya, E.R., Libling, M.M. (2007) Аутичный ребенок: Пути помощи [Аиtistic child: way of helpness]. Moscov: Теревинф.

Nikopoulos, C. K., \& Keenan, M. (2004). Effects of video modeling on social initiations by children with autism. Journal of Applied Behavior Analysis, 37, 93-96.

Nikopoulos, C. K., \& Keenan, M. (2007). Using video modeling to teach complex social sequences to children with autism. Journal of Autism and Developmental Disorders, 37, 678-693.

Owen-DeSchryver, J. S., Carr, E. G., Cale, S. I., \& Blakeley-Smith, A. (2008). Promoting social interactions between students with autism spectrum disorders and their peers in inclusive school settings. Focus on Autism and Other Developmental Disabilities, 23, 15-28.

Owens, G., Granader, Y., Humphrey, A., \& Baron-Cohen, S. (2008). LEGO therapy and the social use of language programme: An evaluation of two social skills interventions for children with high functioning autism and Asperger syndrome. Journal of Autism and Developmental Disorders, 38, 1944-1957.

Petursdottir, A. L., McComas, J., McMaster, K., \& Horner, K. (2007). The effects of scripted peer tutoring and programming common stimuli on social interactions of a student with autism spectrum disorder. Journal of Applied Behavior Analysis, 40, 353-357.

Rayner, C., Denholm, C., \& Sigafoos, J. (2009). Video-based intervention for individuals with autism: Key questions that remain unanswered. Research in Autism Spectrum Disorders, 3, 291-303. 
Reichow, B., Volkmar, F. R., \& Cicchetti, D. V. (2008). Development of an evaluative method for determining the strength of research evidence in autism. Journal of Autism and Developmental Disorders, 38, 1311-1318.

Rogers, S. J. (2000). Interventions that facilitate socialization in children with autism. Journal of Autism and Developmental Disorders, 30, 399-409.

Sansosti, F. J., \& Powell-Smith, K. A. (2008). Using computerpresented social stories and video models to increase the social communication skills of children with high-functioning autism spectrum disorders. Journal of Positive Behavior Interventions, 10, 162-178.

Sarokoff, R. A., Taylor, B. A., \& Poulson, C. L. (2001). Teaching children with autism to engage in conversational exchanges: Script fading with embedded textual stimuli. Journal of Applied Behavior Analysis, 34, $81-84$.

Sawyer, L. M., Luiselli, J. K., Ricciardi, J. N., \& Gower, J. L. (2005). Teaching a child with autism to share among peers in an integrated preschool classroom: Acquisition, maintenance, and social validation. Education and Treatment of Children, 28, 1-10.

Scattone, D. (2008). Enhancing the conversation skills of a boy with Asperger's disorder through Social Stories and video modeling. Journal of Autism and Developmental Disorders, 38, 395-400.

Scheeren, A.M., Koot, H.M., \& Begeer, S. (2012). Social interaction style of children and adolescents with highfunctioning autism spectrum disorder. J Autism Dev Disord, 42, 2046-2055.

Schertz, H. H., \& Odom, S. L. (2007). Promoting joint attention in toddlers with autism: A parent-mediated developmental model. Journal of Autism and Developmental Disorders, 37, 1562- 1575.

Shabani, D. B., Katz, R. C., Wilder, D. A., Beauchamp, K., Taylor, C. R., \& Fischer, K. J. (2002). Increasing social initiations in children with autism: Effects of a tactile prompt. Journal of Applied Behavior Analysis, 35, 79-83.

Sherer, M., Pierce, K. L., Pardes, S., Kisacky, K. L., Ingersoll, B., \& Schreibman, L. (2001). Enhancing conversation skills in children with autism via video technology: Which is better, "self" or "other" as a model? Behavior Modification, 25, 140-158.

Shulzhenko D.I. (2009) Основи психологічної корекиії аутистичних порушень у дітей: монограсрія [Вазе of psycholocial correction of children autistic disorders]. Kiev: Національний педагогічний університет імені М.П.Драгоманова.

Simpson, A., Langone, J., \& Ayres, K. M. (2004). Embedded video and computer based instruction to improve social skills for students with autism. Education and Training in Developmental Disabilities, 39, 240-252.

Skrypnyk, T.V. (2008) Методика дослідження психічних процесів у дошкільників з аутизмом [Method of invеstigation of psychical process for preschool children with autism]. Kiev: Педагогічна думка.

Smith, C., Goddard, S., \& Fluck, M. (2004). A scheme to promote social attention and functional language in young children with communication difficulties and autistic spectrum disorder. Educational Psychology in Practice, 20, 319-333.

Strain, P. S., \& Fox, J. J. (1981). Peer social initiations and the modification of social withdrawal: A review and future perspective. Journal of Pediatric Psychology, 6, 417-433.

Strain, P. S., \& Schwartz, I. (2001). ABA and the development of meaningful social relations for young children with autism. Focus on Autism and Other Developmental Disabilities, 16, 120-128.

Thiemann, K. S., \& Goldstein, H. (2001). Social stories, written text cues, and video feedback: Effects on social communication of children with autism. Journal of Applied Behavior Analysis, 34, 425-446.

Thiemann, K. S., \& Goldstein, H. (2004). Effects of peer tutoring and written text cueing on social communication of school-age children with pervasive developmental disorder. Journal of Speech, Language, and Hearing Research, 47, 126-144.

Vismara, L. A., \& Lyons, G. L. (2007). Using perseverative interests to elicit joint attention behaviors in young children with autism: Theoretical and clinical implications for understanding motivation. Journal of Positive Behavior Interventions, 9, 214-228.

Walton, K.M. \& Ingersoll, B.R. (2012). Improving social skills in adolescents and adults with autism and severe to profound intellectual disability: A review of the literature. J Autism Dev Disord, 2012 DOI 10.1007/ s10803-012-1601-1.

Whalen, C., \& Schreibman, L. (2003). Joint attention training for children with autism using behavior modification procedures. Journal of Child Psychology and Psychiatry, 44, 456-468.

White, S. W., Keonig, K., \& Schaill, L. (2007). Social skills development in children with autism spectrum disorders: A review of the intervention research. Journal of Autism and Developmental Disorders, 37, 1858-1868.

Zercher, C., Hunt, P., Schuler, A., \& Webster, J. (2001). Increasing joint attention, play and language through peer supported play. Autism, 5, 374-398. 